\title{
Environmental Pollution and Nanotechnology
}

\author{
Poorva Mehndiratta ${ }^{1}$, Arushi Jain ${ }^{1}$, Sudha Srivastava ${ }^{1} \&$ Nidhi Gupta $^{1}$ \\ ${ }^{1}$ Department of Biotechnology, Jaypee Institute of Information Technology, Noida, U.P, India \\ Correspondence: Nidhi Gupta, Department of Biotechnology, Jaypee Institute of Information Technology, Noida \\ 201307, U.P, India. Tel: 91-120-259-4211. E-mail: Nidhi.gupta@jiit.ac.in
}

Received: October 8, 2012 Accepted: January 30, 2013 Online Published: March 13, 2013

doi:10.5539/ep.v2n2p49

URL: http://dx.doi.org/10.5539/ep.v2n2p49

\begin{abstract}
Nanotechnology is an upcoming technology that can provide solution for combating pollution by controlling shape and size of materials at the nanoscale. This review provides comprehensive information regarding the role of nanotechnology in pollution control at three different steps viz. Source reduction or pollution prevention, remediation or degradation of pollutants and sensing of pollutants. Due to its large surface area and high surface energy, the nanoparticles have the ability to absorb large amount of pollutants or catalyze reactions at a much faster rate, thus reducing energy consumption during degradation or helps in preventing release of contaminants. The nanosize of the particles also make it possible to reach otherwise inaccessible areas and hence promote in-situ remediation rather than ex-situ remediation. The ability of the nanoparticles to be coated with various ligands and control of surface area to volume ratio by changing the shape of the nanoparticles enables the design of sensors with high selectivity, sensitivity and specificity.
\end{abstract}

Keywords: environment, nanotechnology, pollution, remediation, sensing, prevention

\section{Introduction}

The term "Pollution" has many definitions, one being "the presence of a substance in the environment whose chemical composition or quantity prevents the functioning of natural processes and produces undesirable environmental and health effects" (United States Environmental Protection Agency, 2008). With growing urbanization and increasing population, pollution has become the biggest environmental challenge. Moreover, the technological advancement has also given rise to new pollutants which are increasing at an alarming rate and are above the self remediating ability of the environment. There is an urgent need to find technologies that would reduce these rates/pollution levels to risk-free status in quick and easy manner. Nanotechnology is being explored to provide new solution for cleaning environment and improving the performance of conventional technologies. This technology is also explored for combating pollution by reducing the release or preventing the formation of pollutants. US National Nanotechnology initiative has identified "Environmental improvement" as one of the eight crosscutting areas of nanotechnology (Tratnyek \& Johnson, 2006).

Nanotechnology is the science of petite particles with dimensions in the order of $10^{-9} \mathrm{~m}$, These minuscule particles are subject to the physical and chemical laws, that otherwise; do not apply to the particles of larger sizes. Due to enormous surface area to mass ratio, nanoparticles exhibit exclusive properties. The unique properties of these nanosized materials have resulted in the use of nanoparticles in various fields like biomedicine, pharmaceuticals, cosmetics, and environment. 


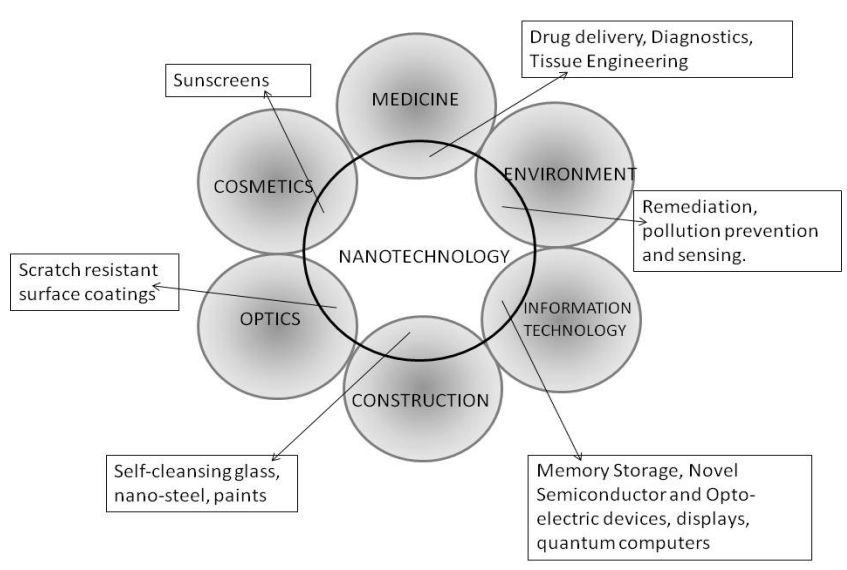

Figure 1. Nanotechnology is an all encompassing technology with wide applications in almost every discernible field

The focus of the review lies in the emerging role of nanotechnology in addressing environmental problems, which though interesting and creditworthy, is underutilized. It has been applied to the three key areas associated with Pollution, namely-Sensing, Remediation and Pollution Control.

\section{Remediation}

Remediation is the science of removal or reduction of pollutants from the environment using chemical or biological means. Recent advancements have made the control and reduction of contaminants in soil, sediments and water the major environmental issue. The conventional techniques like disposal to landfill, isolation are some-what effective but expensive and take a long time to achieve target goals (Salipira, Mamda, Krause, Malefetse, \& Durbach, 2007). These techniques also produce undesirable by-products, like during trichloroethylene in-situ remediation where dichloroethylenes and vinyl chloride are usually intermediate by-products. Also, contaminants like chlorinated hydrocarbons migrate to the water table, and sometimes reach the underlying zone making it extremely difficult to remediate aquifers with standard existing procedures. All these limitations can be effectively targeted by nanotechnology (Masciangioli \& Zhang, 2003). Nanoparticles offer numerous advantages owing to their small size and high surface area. These nanoparticles can be easily transported with the flow of water (Karn, Kuiken, \& Otto, 2009) and hence, can be used for treating underground contaminants without excavation. Because of their extremely small size, these particles can be injected into very small spaces and even remain active for long duration of time (Zhang, 2003). The movement of these nanoscale particles is largely controlled by gravitational sedimentation. The large surface area leads to high enzymatic activity. In addition, to being used as free particles, nanoparticles can be anchored on a solid matrix and can be used for waste water treatment or gaseous stream treatment (Zhang, 2003).

Nanotechnology offers great diversity in the types of materials- carbon nanotubes, nanoscale zeolites, dendrimers, enzymes, bimetallic particles and metal oxides that can be used for the purpose of remediation. Iron nanoparticles are the most commonly used remediation tool (Zhang, Wang, \& Lien, 1998; Ponder, Darab, \& Mallouk, 2000; Kanel, Manning, Charlet, \& Choi, 2005; Shipley, Engates, \& Guttner, 2010). Iron has an integral role in the remediation of environmental pollutants due to its reducing properties as an electron donor. It is a powerful reductant making it possible to employ it for the remediation of any contaminant that can be degraded by reduction. Karn et al. (2009) discussed the degradation of poly halogenated organic compounds and heavy metals using iron nanoparticles. During the reaction, iron nanoparticles are oxidized to ferric/ferrous ion and the halogenated organic contaminant is reduced. Also, because of the versatile deployment ability of iron nanoparticles, their site remediation abilities cover wide range of contaminants. Successful degradation of pesticides like 2,4 Dichlorophenoxyacetic acid (2, 4-D) using magnetic nanoparticles have also been reported by Fang, Si, Tian, Zhang, and Zhou (2011). Iron nanoparticles can be used to remediate surface contaminants like petrochemical compounds and even sub-surface contaminants like pesticides, organic solvents, fertilizers and heavy metals (Figure 2). 


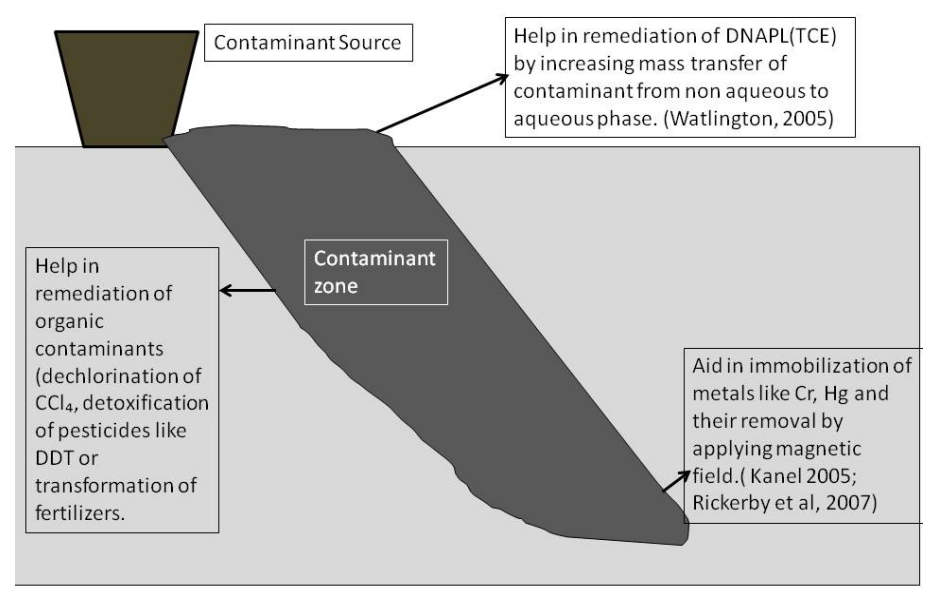

Figure 2. Schematic diagram representing the use of iron nanoparticles in the degradation of various environmental contaminants like organic, inorganic and petrochemical compounds

In certain conditions, like when present in large concentrations, the iron nanoparticles may come closer due to magnetic and van der waals forces and agglomerate. This agglomeration adversely affects the reactivity of the nanoparticles because the specific surface area decreases and causes the particles to settle down. To overcome this problem Bezbaruah, Krajangpan, Chisholm, Khan, and Bermudez (2008) have all reported the use of calcium alginate beads to entrap the iron nanoparticles, so as to reduce their motility and overcome agglomeration. They performed degradation studies, using nitrate as the model compound, to check the effectiveness of entrapped nanoparticles against bare nanoparticles. It was observed that there was a slight reduction in the degradation rates by entrapped nanoparticles, probably because of mass diffusion limitations. But after statistical analysis it was proven that the difference was not significant. Hence, bipolymer entrapment could be employed in conditions requiring low motility and/or relatively stationary particles. Similar study, involving immobilization with a support in order to prevent agglomeration, has been performed by Ponder et al. (2000) by preparing nanoscale particles by borohydride reduction in presence of a support material like polymeric resin, silica gel etc. They compared the reduction of $\mathrm{Cr}(\mathrm{VI})$ and $\mathrm{Pb}(\mathrm{II})$ and found that remediation using supported nZVI led to 30 times higher rates as compared to iron powder/fillings in terms of the number of moles of iron.

The biggest disadvantage of using iron nanoparticles is, that while orchestrating the reduction of contaminant, the nanoparticles itself gets oxidised and cannot be re-used. Zhang et al. (1998) proposed the use of Nanoscale bi-metallic particles, iron or zinc nanoparticles coated with catalyst, palladium or platinum, in the treatment of chlorinated solvents to benign hydrocarbons. Bimetallic nanoparticles like Pd-Au nanoparticles offer the solution to this problem as they show a catalytic nature and can be used repeatedly (Nutt, Hughes, \& Wong, 2005). Zhang et al. (2010) analyzed the efficiency of ferromagnetic carbon coated Fe nanoparticles in the removal of $\mathrm{Cr}$ (VI) from waste water via carbon shell physical adsorption mechanism. The technique involves covering bare metal $(\mathrm{Co}, \mathrm{Fe}, \mathrm{Ni})$ nanoparticles in a protective shell made of silica, polymer carbon or noble metals, such that the magnetic nanoparticles don't ignite at room temperature or get oxidised upon exposure to air. Carbon shell technique is more cost-effective and efficient when compared to conventional techniques like solvent extraction, ion-exchange, osmosis etc. This is because the carbon shell of the nanoparticles adsorbs the Cr (VI) on its surface (Hsu, Wang, Lin, Sheng, \& Lee, 2009). After the treatment duration, the magnetic nanoparticles can be collected by the use of a magnet and subsequently recycled. Up to $95 \%$ wt $\mathrm{Cr}$ (VI) can be removed within 2 hour treatment procedure.

Salipira et al. (2003) have reported the use of multiwalled carbon nanotubes functionalized with a mixture of nitric and sulphuric acid in the removal of organic pollutants like polyaromatic hydrocarbons, dioxins and polychlorinated biphenyls from water. They tested the degradation of model compound trichloroethylene (TCE), which is a known endocrine disrupting chemical, by cyclodextrin polyurethanes polymerised with carbon nanotubes. The presence of antibiotics in aquatic environment has also raised serious issues. The conventional methods consist of the use of non porous activated carbon and non porous graphite. In comparison to these techniques, the use of single walled and multi-walled carbon nanotubes has a better adsorbent to solution distribution coefficient and adsorption affinity for tetracycline. Strong adsorption interactions are the major reasons for the high affinity. 
Photo-remediation by semiconductor nanoparticles is based on the reduction or oxidation of adsorbed contaminant upon band gap excitation of the nanoparticles. The $\mathrm{TiO}_{2}$ nanoparticle can either be excited by UV-radiation leading to the release of $\mathrm{OH}^{-} / \mathrm{OH}$. Ions/radicals which may oxidize or reduce the adsorbed contaminant (Direct Method), or $\mathrm{TiO}_{2}$ nanoparticles can help in the generation of photocurrent, i.e. adsorbed contaminant or dye transfers electron to nanoparticles upon excitation by visible light. In this indirect process the contaminant undergoes oxidative degradation (Kamat \& Meisel, 2003). Further modifications, like doping of semiconductor nanoparticles with transitional metal elements, has been shown to increase the photoresponse of $\mathrm{TiO}_{2}$ nanoparticles to visible light (Paola et al., 2002; Anpo et al., 1998). $\mathrm{ZnO}$ semiconductor nanocluster shows a promising role in environmental application as it emits strongly in the visible region. $\mathrm{ZnO}$ nanoparticles can be used to effectively degrade organic contaminants like PCBs adsorbed to its surface (Kamat et al., 2003).

\subsection{Bioremediation}

Bioremediation of harmful organic contaminants like carbazole and dibenzothiophene has been successfully reported by different groups using variety of micro-organisms (Maeda et al., 2009; Singh et al., 2011) but their industrial application is limited by the lack of re-usability and difficulty in downstream processing i.e. separation of cells from the solution. Also, limited bioavailability of these compounds in water has led to lower rates of activity as compared to possible efficiency.

Nanotechnology has played a role in microbial remediation. Increasing the solubility/bioavailability and subsequently the degradation rate, by far, has been the biggest challenge in bioremediation. In the present scenario, surfactant micelles are used to increase the solubility of the contaminant but these tend to interact with the liposome of microorganisms and also break down upon contact with soil and thus limiting the efficiency of bioremediation. Recent advances in nanotechnology have shown a promising step in this direction. Tungittiplakorn, Cohen, and Lion (2004) have reported an increase in the solubilisation rate of model remediation compound Phenanthrene (PHEN) by using amphiphilic polyurethane (APU) nanoparticles. These particles, made of polyurethane acrylate anionmer (UAA) or poly(ethylene) glycol (PMUA) precursor chains, have hydrophobic interiors that show high affinity for PHEN. They enhance PAH desorption and mobility by forming a nanoparticle-suspension which competes with NAPLs (Warapong et al., 2005). As opposed to surfactant, the affinity of the nanoparticles to hydrophobic contaminant can be increased by modifying the hydrophobic segment of the precursor chain and the mobility can be increased by controlling the charge density of the modified nanoparticles.

Another advantage offered by nanoparticles in bioremediation, is in the form of Magnetite nanoparticles. Magnetite nanoparticles are formed by the co-precipitation of ferrous and ferric salts under inert conditions. This technology imparts great industrial applicability in terms of easier separation, re-usability, and cost-effectiveness. Li, Gao, Li, Xing, and Liu (2009) have reported the use of magnetite nanoparticles by coating them on dibenzothipohene-desulfurizing bacterial strain $R$. erthyropolis LSSE8-1 and P. delafiedelii and analyzing their biodesulfurization activity. The cells coated with ammonium oleate modified magnetite nanoparticles showed repeated biodesulfurization activity and could be collected on the surface of the flask by using an external magnet. The use of magnetite nanoparticles also showed increased desulfurization activity.

\section{Sensing}

Continuous monitoring or sensing of pollutants is essential to protect the environment from the harmful effect of the contaminants. Various protection agencies have imposed a limitation on the maximum permissible concentration of known pollutants in the environment. Physical, chemical and biological assays are available to determine the type and the concentration of the pollutant present. Even though these assays are highly sensitive and specific, they require sampling and subsequent analysis of the sample in the lab. These methods are time consuming, expensive and require a lot of expertise. Moreover, due to processing of the sample these techniques are unable to determine the exact composition and nature of the pollutant under field conditions. A sensor assists in infield environmental monitoring but sacrifices the detection limit and specificity.

Research is focused on improving the selectivity, specificity and sensitivity of the sensors for environmental monitoring either by targeting the binding between the contaminant and the recognition element or optimizing the transduction and electronic interface to the sensing layer. Nanotechnology is playing a key role in targeting these issues via several ways. First, the ability of the nanoparticles to be coated with wide range of chemical and biological ligands helps in imparting the specifity to the sensor. Several scientists have reported the capping of nanoparticles with various ligands like proteins, DNA, enzymes etc. The binding between these ligands and analyte is highly specific. Secondly, the surface to volume ratio of the nanoparticles can be easily controlled by varying the size and shape of the nanoparticles thus imparting control over the interaction quality with the 
analyte molecule. Thirdly, the ability to construct nanoparticles of varying metals helps in improving the conductivity and thus, the sensitivity.

Sensors based on nanoparticles can be used for sensing organic contaminants, inorganic contaminants or biological organisms. Scientists have proposed the use of semiconductor nanostructures using porous silicon for detection of organic contaminants (Stefano, Moretti, Rendina, \& Rotiroti, 2005). Porous silicon exhibits the phenomena of photoluminescence and this luminescence is quenched in the presence of organic or inorganic molecule. Using this technology pesticide concentration as low as $1 \mathrm{ppm}$ could be detected (Stefano et al., 2005). The quenching of photoluminescence by organic contaminant is attributed to both energy transfers to the triple substrate of the organic substrate, and to the electron transfer from the conduction band of silicon nanocrystal to the vacant orbital of the quencher. Carbon nanotube based sensors are used for sensing various gases like $\mathrm{NH}_{3}$, $\mathrm{NO}_{2}$ or $\mathrm{O}_{3}$. Upon contact with these gases the electrical resistance of the nanotubes changes so drastically, that it can be recorded.

The detection of various heavy metals, like $\mathrm{Pb}, \mathrm{Hg}, \mathrm{Cd}$, using nanoparticles is either fluorescence based or calorimetric based. Kim et al. (2001) and Sugunun et al. (2005) functionalized gold nanoparticles with 11mercaptoundecanoic acid and chitosan respectively for the detection of heavy metal ions like lead, cadmium and mercury. Mercaptoundeanoic acid and chitosan are metal chelating agents. Binding of heavy metal ions to these metal chelators results in aggregation of the nanoparticles yielding a shift in wavelength absorption and ultimately resulting in colour change from red to blue. Though it is not specific for a particular ion but the detection of heavy metal ions in general was very sensitive. Based on similar principle, specific sensors were developed. Liu and $\mathrm{Lu}$ (2004) developed a sensor for Pb detection. For this sensor, the gold nanoparticles were coated with lead dependent DNA enzyme. In the absence of lead, enzyme induced aggregation of nanoparticles where as in the presence of lead, activated enzyme cleaves the substrate and the aggregation was prevented. This resulted in a shift in wavelength absorption.

Huang, Wang, and Yan (2006) reported selective detection of mercury by Au nanoparticles adsorbed with Rhodamine $\mathrm{B}$, which is a highly fluorescent molecule. Its fluorescence is quenched due to its binding with $\mathrm{Au}$ nanoparticles. The presence of $\mathrm{Hg}$ in the solution results in the release of Rhodamine and hence restores the fluorescence; the intensity of which is related to the amount of $\mathrm{Hg}$ present in the solution. The specificity towards mercury was provided by modifying the nanoparticle surface with thiol ligands and adding a chelating agent to the solution. The nanosensor so developed was highly sensitive and selective, and could detect very low concentration of mercury ( $2 \mathrm{ppb})$ as compared to other fluorescent chemosensor that were available. Also, the detection time was reduced to less than 10 minutes.

Biological contaminants include living organisms (generally bacteria) or their by-products that can be toxic to human health. The major bacterial pollutant belongs to enterobacteriaceae family. Lin et al. (2002) proposed the use of mannose encapsulated gold nanoparticles for the detection of e.coli, as mannose has affinity towards type I pilli of E.coli. It was observed that nanoparticles encapsulated mannose had higher affinity towards E.coli as compared to free mannose. Rather than sensor specific for a particular microorganism, Yonzon et al. (2005) developed a silver nanoparticles based universal system for the detection of bacteria. Silver nanoparticles were functionalized with maltose that showed affinity towards carbohydrate binding protein concanavalin $\mathrm{A}$. It was also observed that concanavalin A showed better affinity for maltose as compared to galactose. Rather than detection, Huang et al. (2010) proposed the removal of bacteria from the media by amine functionalized magnetic nanoparticles. The positive charge on the surface of the nanoparticles showed electrostatic interaction with negative charge on the bacterial surface. The efficiency for bacterial removal from water samples was 88.5\%. Ho, Tsai, Lin, and Chen (2004) coated gold nanoparticles with IgG and explored the interaction of IgG with protein for sensing pathogenic microorganism. This interaction proved successful for sensing S. aureus and S. saprophyticus. Similar studies were performed for detection of other pathogenic microorganisms as well. With a view to purify water, IgG antibody was coated on the surface of magnetic nanoparticles. The trapped microorganisms were removed by applying an external magnet.

Quantum dots (QD) are also used as a fluorescent labeling system for detection of microorganisms. Zhu, Ang, and Liu (2004) reported that conjugation of antibody to QD can be used for the detection of pathogenic microorganisms' viz. cryptosporidium and Giardia. Similar results were also reported for Salmonella typhimurium and mutant e.coli strains. Goldman et al. (2004) proposed the simultaneous detection of four different toxins viz. cholera toxin, ricin, shiga-like toxin 1, and staphylococcal enterotoxin B using quantum dot shells and antibodies as probes. Quantum dots exhibit superior photostability and multiplexing analysis as compared to organic dyes. 
Apart from these biological contaminants, the detection of Bacillus specifically is gaining importance due to its potential as a bioterrorism weapon. The virulence of $B$. anthracis is encoded by capsule and a triparitite exotoxin. The sensor for bacillus spores utilizes calcium dipicilonic acid (CaDPA) as a biomarker. CaDPA is specifically present in the spores and doesn't have any interfering molecule. It was reported that deposition of spores on the surface of AgFON (Silver film over nanoparticles) resulted in a SERS spectrum unique to CaDPA (Yonzon et al., 2005). The system was able to detect spore concentration at less than the life threatening dose. Yilmaz, Hsu, Reinhoudt, Velders, and Huskens (2010) developed a surface assisted fluorescent sensing system for detection of anthrax spores. The binding of DPA to the receptor was detected using ultra violet light. DPA bonded receptors resulted in the emission of blue light whereas no bonding resulted in red light. The ratio of red to blue light could be used for calculating the concentration of spores. The sensors so developed were more sensitive and effective than the current methods available and could be reused.

Zhang, Anderson, Huarng, and Alocilja (2011) developed a nanosensor based on the detection of exotoxin produced by bacillus. The exotoxin is encoded by three genes viz. cya, pag and lef. The sensor developed was based on the detection of gene encoding for the toxin pag. It consisted of two nanoparticles viz. gold and magnetite. Gold nanoparticles were coated with a 1st DNA probe specific for target DNA and nanoparticles tracer labeled barcode DNA. The magnetite nanoparticles were coated with 2nd DNA probe specific for target DNA. In the presence of the target a sandwich structure consisting of magnetite and gold nanoparticles was formed. Magnetic field was applied to separate the complex from the mixture and the presence of the target DNA was detected using nuclear tracer.

\section{Pollution Prevention and Control}

Pollution prevention is defined as the reduction of pollutants at the source. It is a promising mean of protecting the environment and encompasses various activities like- using products causing less pollution during manufacturing, use or disposal. Pollution can also be prevented by taking steps to reduce energy consumption or by preventing release of contaminant produced during manufacturing processes. The pollution control hierarchy as established in pollution prevention act of 1990 places pollution prevention at the top of its list. In spite of of the significance attached to pollution prevention in pollution control, even today the main focus for technology development is remediation rather than prevention. Nanotechnology can play a key role in pollution prevention. According to a recent study, United States saved an estimated $\$ 100$ billion in a year by using nanotechnology-based home lighting. The total amount of energy consumption came down by around $10 \%$ and the carbon emissions reduced by 200 million tons per year (National Nanotechnology Initiative, 2001).

\subsection{Nanomaterial and Source Reduction}

Metal oxide nanocatalysts, chiefly gold nanocatalyst, show promising results for preventing or reducing the pollution at the source. This is achieved either by pollution control applications such as air cleaning or as low light-off autocatalysts and purification of hydrogen streams used for fuel cells. 27 patents have been granted during 2001 on gold catalyst for various pollution control activities and since then it has shown an upward trend. Based on analysis by World Gold Council, the focus of the patents for pollution prevention by gold nanocatalyst was split by subject; with chemical processing having the maximum share of $46 \%$ followed by pollution Control (29\%), Catalyst Manufacture/Regeneration (15\%) and Fuel Cells (10\%). The main attribute governing gold nanocatalyst common usage is its high activity rate under mild conditions thus reducing the running costs of chemical plants. In addition, gold nanocatalysts also possess low activation energy and activity enhancement by moisture. CO oxidation can be done over a wide span of temperature ranging from $90 \mathrm{~K}$ to $400 \mathrm{~K}$ (Haruta, 2003). $\mathrm{Au}$ nanoparticles have hemispherical shapes and the perimeter interfaces around the particles act as reaction sites. $\mathrm{CO}$ gets adsorbed on the edge and step sites of Au surfaces and $\mathrm{O}_{2}$ adsorbs on the support surfaces. Both then react in the interface region.

Grisel and Nieuwenhuys (2001) have shown that using $\mathrm{Au} / \mathrm{MgO} / \mathrm{MnOx}$ at $20^{\circ} \mathrm{C}$, carbon monoxide is oxidized much more readily than hydrogen. Gold nanocatalyst is being used commercially by "Mintek", South Africa in a prototype air purification unit which removes carbon monoxide from the air at room temperature. It is designed to be used in restaurants, hospitals, hotels and offices. Gold nanocatalysts are also used in oxidizing carbon monoxide to remove it from the hydrogen feeds used in fuel cells thus making the fuel cells more efficient (Cameron, Holliday, \& Thompson, 2002).

Titanium dioxide nanoparticles possess photocatalytic properties and hence have been used to build self-cleaning surfaces that reduce the existing pollution. It is also a potent oxidizing agent when exposed to UV radiation. This helps in the breakdown of VOCs, nitrous oxides and other pollutants into less harmful species (Parkin \& Palgrave, 2005). Another widely used structure in separation and catalysis is an aluminosilicate molecular sieve, 
otherwise known as a zeolite. It is a well defined porous crystalline solid. Nanosized zeolites (10-100 nm) have been developed to oxidize hydrocarbons, like toluene to benzaldehyde. They make oxidation eco-friendly due to two main reasons. First, the reaction is triggered by visible light, in turn reducing the energy consumption. Secondly, low-energy reaction pathways are followed that help in eliminating wasteful secondary photoreactions and hence increase the yield of the desired product (Panov, Larson, Totah, Larsen, \& Grassian, 2000).

\subsection{Sustainable Development}

Nanotechnology also helps in manufacturing eco-friendly materials by replacing currently used toxic materials. Choi (1999) proposed the use of carbon nanotubes instead of cathode ray tubes (with lead as one of the component) in the manufacture of computer monitors. CRT monitors using carbon nanotubes prevent pollution by eliminating the use of toxic heavy metals and drastically reducing material and energy requirements, while providing enhanced performance.

Pizzini, Acciarri, and Binetti (2005) studied the performance of nanoporous silicon in photovoltaic cells. Its porous structure leads to quantum confinement and an increase in the bandgap, while the increased light absorption results in higher internal quantum efficiency. In search for an alternative to Si photovoltaics, Gratzel (2003) developed organic solar cells using $\mathrm{TiO}_{2}$ nanoparticles coated with an organic dye to convert light into energy by a process analogous to photosynthesis. Even though the conversion efficiency is only $10 \%$, this type of cell can be manufactured from inexpensive, low purity materials using simple technique. The ALISTORE European Network of Excellence on Advanced Lithium Energy Storage Systems has been working on increasing the power output of rechargeable lithium batteries from the present 200 to $300 \mathrm{Wh} / \mathrm{kg}$ by using nanostructured electrode materials namely lithium cobalt oxide, iron fluoride, cobalt chloride, rubidium oxide and nickel phosphide (Tarascon \& Armand, 2001).

Nanofabrication methods are followed to get an effective control over the shape, size, and position of nanoscale metals used in a catalyst. The ones used in automobiles contain platinum group metals (PGM). Researchers proposed that an automotive catalyst manufactured using nanofabrication would result in a highly reduced PGM loading level. This would decrease the amount of energy consumed, improve the quality of environment, and lead to a sustainable resource usage (Lloyd, Lave, \& Matthews, 2005).

\section{Conclusion}

Nanotechnology is a "breakthrough" technology and has the potential to offer several benefits that are not offered by other conventional technologies. The major limitation associated with the commercialization of this technology, is the safety issue associated with the use of nanoparticles.

However, our knowledge regarding the toxic effects of nanoparticles is limited. Most nanoparticles in technical applications are functionalized and toxicity studies are usually performed using pure nanoparticles. Moreover, toxicological studies are performed on mammalian cells only. They are carried out in a cell culture medium containing a mixture of proteins and other biological compounds. Results from such studies therefore cannot be directly correlated to environmental conditions (Limbach et al., 2005). In this regard the U.S. Environmental Protection Agency has issued screening test for hazard identification of engineered nanomaterials (Aricò, Bruce, Scrosati, Tarascon, \& Schalkwijk, 2005).

Doubtless, nanotechnology and in particular the nanoparticles will have great positive effects on the various fields of environmental technology. Still, the major limitation would be the lack of information regarding the toxicity of engineered nanoparticles. We have to keep in mind that nanotechnology has a Janus face and the potential for undesirable human health outcome cannot be overruled. To make this technology commercially viable safety guidelines for nanotechnology industry should be enforced that involve toxicity screening of engineered nanoparticles under environmental conditions.

\section{References}

Aricò, A. S., Bruce, P., Scrosati, B., Tarascon, J. M., \& Schalkwijk, W. (2005). Nanostructured materials for advanced energy conversion and storage devices. Nat. Mater., 4, 366-377. http://dx.doi.org/10.1038/nmat1368

Bezbaruah, A. N., Krajangpan, S., Chisholm, B. J., Khan, E., \& Bermudez, J. J. E. (2008). Entrapment if iron nanoparticles in calcium alginate beads for groundwater remediation applications. Journal of Hazardous Materials, 166, 1339-1343. http://dx.doi.org/10.1016/j.jhazmat.2008.12.054

Cameron, D. S., Holliday, R. J., \& Thompson, D. T. (2002). Grove Fuel Cell Event, Amsterdam, Poster P3P.4 
Choi, W. B. (1999). Fully sealed, high-brightness carbon-nanotube field-emission display. Applied Physics Letters, 75, 3129-3131. http://dx.doi.org/+10.1063/1.125253

Fang, G., Si, Y., Tian, C., Zhang, G., \& Zhou, D. (2011). Degradation of 2,4-D in soils by $\mathrm{Fe}_{3} \mathrm{O}_{4}$ nanoparticles combined with stimulating indigenous microbes. Environmental Science \& Pollution Research, 19, 784-793. http://dx.doi.org/10.1007/s11356-011-0597-y

Goldman, E. R., Clapp, A. R., Anderson, G. P., Uyeda, H. T., Mauro, J. M., Medintz, I. L., \& Mattoussi, H. (2004). Multiplexed Toxin Analysis Using Four Colors of Quantum Dot Fluororeagents. Analytical Chemistry, 76, 684. http://dx.doi.org/10.1021/ac035083r

Gratzel, M., (2003) Dye sensitized solar cells. Journal of Photochemistry and Photobiology: C, 4, 145. http://dx.doi.org/10.1016/S1389-5567(03)00026-1

Grisel, R. J. H., \& Nieuwenhuys, B. E. (2001). Selective Oxidation of CO over Supported Au Catalysts. Journal of Catalysis, 199(1), 48-59. http://dx.doi.org/10.1006/jcat.2000.3121

Gupta, N., Roychoudhury, P. K., \& Deb, J. K. (2005). Biotechnology of desulfurization of diesel: prospects and challenges. Applied Microbial Biotechnology, 66(4), 356-366. http://dx.doi.org/10.1007/s00253-004-1755-7

Haruta, M. (2002). Catalysis and applications of gold nanoparticles deposited on metal oxides. Studies in Surface Science and Catalysis, 145, 31-38. http://dx.doi.org/10.1023/A:1020181423055

Ho, K. C., Tsai, P. J., Lin, Y. S., \& Chen, Y. C. (2004). Using biofunctionalized nanoparticles to probe pathogenic bacteria. Analytical Chemistry, 76(24), 7162-7168. http://dx.doi.org/10.1021/ac048688b

Hsu, N. H., Wang, S. L, Lin, Y. C., Sheng, G. D., \& Lee, J. F. (2009). Reduction of Cr(VI) by crop residue derived black carbon. Environmental Science and Technology, 43, 8801-8806. http://dx.doi.org/10.1021/es901872x

Huang, Y. F., Wang, Y. F., \& Yan, X. P. (2010). Amine-Functionalized Magnetic Nanoparticles for Rapid Capture and Removal of Bacterial Pathogens. Environmental Science and Technology, 44(20), 7908-7913. http://dx.doi.org/10.1021/es102285n

Kamat, P. V., \& Meisel, D. (2003). Nanoscience opportunities in environmental remediation. C R Chimie, 6, 999-1007. http://dx.doi.org/10.1016/j.crci.2003.06.005

Kanel, S. R., Manning, B., Charlet, L., \& Choi, H. (2005). Removal of Arsenic(III) from Groundwater by Nanoscale zero-valent iron. Environment Science and Technology, 39, 1291-1298. http://dx.doi.org/10.1021/es048991u

Karn, B., Kuiken, T., \& Otto, M. (2009). Nanotechnology and in Situ Remediation: A Review of the Benefits and Potential Risks. Environmental Health Perspective, 117, 1823-1831. http://dx.doi.org/10.1289/ehp.0900793

Li, Y. G., Gao, H. S., Li, W. L., Xing, W. L., \& Liu, H. Z. (2009). In situ magnetic separation and immobilization of dibenzothiophene-desulfurizing bacteria. Bioresource Technology, 100(21), 5092-5096. http://dx.doi.org/10.1016/j.biortech.2009.05.064

Limbach, L. K., Li, Y., Grass, R. N., Brunner, T. J., Hintermann, M. A., Muller, M., ... Stark, W. J. (2005). Oxide Nanoparticle Uptake in Human Lung Fibroblasts: Effects of Particle Size, Agglomeration, and Diffusion at Low Concentrations. Environmental and Science Technology, 39(23), 9370-9376. http://dx.doi.org/10.1021/es051043o

Lin, C. C., Yeh, Y. C., Yang, C. Y., Chen, C. L., Chen, G. F., Chen, C. C., \& Wu, Y .C. (2002). Selective Binding of Mannose-Encapsulated Gold Nanoparticles to Type 1 Pili in Escherichia coli. Journal of the American Chemical Society, 124(14), 3508-3509. http://dx.doi.org/10.1021/ja0200903

Liu, J., \& Lu, Y. (2004). Accelerated Color Change of Gold Nanoparticles Assembled by DNAzymes for Simple and Fast Colorimetric $\mathrm{Pb}^{2+}$ Detection. Journal of the American Chemical Society, 126(39), 12298-12305. http://dx.doi.org/10.1021/ja046628h

Lloyd, S. M., Lave, L. B., \& Matthews, H. S. (2005). Life cycle benefits of using nanotechnology to stabilize platinum-group metal particles in automotive catalysts. Environmental and Science Technology, 39(5), 1384-92. http://dx.doi.org/10.1021/es049325w 
Maeda, R., Nagashima, H., Widada, J., Iwata, K., \& Omori, T. (2009). Novel marine carbazole degrading $\begin{array}{llll}\text { bacteria. } & \text { FEMS } & \text { Microbiology 203-209. }\end{array}$ http://dx.doi.org/10.1111/j.1574-6968.2009.01497.x

Masciangioli, T., \& Zhang, W. X. (2003). Environmental Technologies at the nanoscale. Environ. Sci. Technol., 37, 102-108. http://dx.doi.org/10.1021/es0323998

Nutt, M. O., Hughes, J. B., \& Wong, M. S. (2005). Designing Pd-on-Au Bimetallic Nanoparticle Catalysts for Trichloroethene Hydrodechlorination. Environmental and Science Technology, 39, 1346-1353. http://dx.doi.org/10.1021/es048560b

Okx, J. P., Horijk, L., \& Stein, A. (1996). Managing soil remediation problems. Environmental Science \& Pollution Research, 3(4), 229-235. http://dx.doi.org/10.1007/BF02986966

Panov, A. G., Larson, R. G., Totah, N. I., Larsen, S. C., \& Grassian, V. H. (2000). Photooxidation of Toluene and $p$-Xylene in Cation-Exchanged Zeolites X, Y, ZSM-5, and Beta: The Role of Zeolite Physicochemical Properties in Product Yield and Selectivity. The Journal of Physical Chemistry, B104, 5706-5714. http://dx.doi.org/10.1021/jp000831r

Parkin, I. P., \& Palgrave, R. G. (2005). Self-cleaning coatings. Journal of Materials Chemistry, 15, 1689. http://dx.doi.org/10.1039/B412803F

Pizzini, S., Acciarri, M., \& Binetti, S. (2005). From electronic grade to solar grade silicon: chances and challenges in photovoltaics. Physica Status Solidi, A202, 2928. http://dx.doi.org/10.1002/pssa.200521104

Ponder, S. M., Darab, J. G., \& Mallouk, T. E (2000). Remediation of Cr(VI) and Pb(II) Aqueous solutions using supported nanoscale zero-valent iron. Environmental Science and Technology, 34, 2564-2569. http://dx.doi.org/10.1021/es9911420

Rickerby, D. G., \& Morrison, M. (2007). Nanotechnology and the environment: A European perspective. Science and Technology of Advanced Materials, 8(1), 19-24. http://dx.doi.org/10.1016/j.stam.2006.10.002

Salipira, K., Mamda, B. B., Krause, R. W., Malefetse, T. J., \& Durbach, S. H. (2007). Carbon nanotubes and cyclodextrin polymers for removing organic pollutants from water. Environmental Chemistry Letters, 5, 13-17. http://dx.doi.org/10.1007/s10311-006-0057-y

Shipley, H. J., Engates, K. E., \& Guttner, A. M. (2010). Study of iron oxide nanoparticles in soil for remediation of arsenic. Journal of Nanoparticle Research, 13, 2387-2397. http://dx.doi.org/10.1007/s11051-010-9999-x

Singh, G. B., Gupta, S., Srivastava, S., \& Gupta, N. (2011). Biodegradation of Carbazole by Newly Isolated Acinetobacter spp. Bulletin of Environmental Contamination and Toxicology, 87(5), 522-526. http://dx.doi.org/10.1007/s00128-011-0382-0

Singh, G. B., Srivastava, A., Saigal, A., Aggarwal, S., Bisht, S., Gupta, S., ... Gupta, N. (2011). Biodegradation of carbazole and dibenzothiophene by bacteria isolated from petroleum-contaminated sites. Bioremediation Journal, 15, 189-195. http://dx.doi.org/10.1080/10889868.2011.624142

Stefano, L. D., Moretti, L., Rendina, I., \& Rotiroti, L. (2005). Pesticides detection in water and humic solutions using porous silicon technology. Sensors and Actuators B: Chemical, 111-112(11), 522-525. http://dx.doi.org/10.1016/j.snb.2005.03.047

Sugunan, A., Thanachayanont, C., Dutta, J., \& Hilborn, J. G. (2005). Heavy-metal ion sensors using_chitosan-capped gold nanoparticles. Science and Technology of Advanced Materials, 6(3), 335-340. http://dx.doi.org/10.1016/j.stam.2005.03.007

Tarascon, J. M., \& Armand, M. (2001). Issues and challenges facing rechargeable Lithium batteries Nature, 414, 359. http://dx.doi.org/10.1038/35104644

Tratnyek, P. G., \& Johnson, R. L. (2006). Nanotechnologies for environmental cleanup, Nano Today, 1, 44-48. http://dx.doi.org/10.1016/S1748-0132(06)70048-2

Tungittiplakorn, W., Cohen, C., \& Lion, L.W. (2005). Engineered Polymeric Nanoparticles for Bioremediation of Hydrophobic Contaminants. Environmental Science and Technology, 39, 1354-1358. http://dx.doi.org/10.1021/es049031a

Watlington, K. (2005). Emerging nanotechnologies for site remediation and wastewater treatment. U.S EPA, Technology Innovation and Field Services Division, Washington, DC, 2005. 
Yilmaz, M. D., Hsu, S. H., Reinhoudt, D. N., Velders, A. H., \& Huskens, J. (2010). Ratiometric Fluorescent Detection of an Anthrax Biomarker at Molecular Printboards. Angewandte Chemie International Edition, 49, 5938-5941. http://dx.doi.org/10.1002/ange.201000540

Yonzon, C. R., Stuart, D. A., Zhang, X., McFarland, A. D., Haynes, C. L., \& Van Duyne, R. P. (2005). Towards advanced chemical and biological nanosensors-An overview. Talanta, 67, 438-448. http://dx.doi.org/10.1016/j.talanta.2005.06.039

Zhang, D., Anderson, M. J., Huarng, M. C., \& Alocilja, E. C. (2011). Nanoparticle-Based Biobarcoded DNA Sensor for the Rapid Detection of pagA Gene of Bacillus Anthracis. Nanotechnology, 23(21), 4756-4764. http://dx.doi.org/10.1109/TNANO.2011.2165965

Zhang, D., Wei, S., Kaila, C., Su, X., Wu, J., Karki, A. B., ... Guo, Z. (2010). Carbon-stabilized iron nanoparticles for environmental remediation. $\quad$ Nanoscale, $2, \quad 917-919$. http://dx.doi.org/10.1039/C0NR00065E

Zhang, W. X. (2003). Nanoscale iron particles for environmental remediation: An overview. Journal of Nanoparticle Research, 5, 323-332. http://dx.doi.org/10.1023/A:1025520116015

Zhang, W. X., Wang, C. B., \& Lien, H. L. (1998). Treatment of Chlorinated organic contaminants with nanoscale bimetallic particles. Catalysis Today, $387-395$. http://dx.doi.org/10.1016/S0920-5861(98)00067-4

Zhu, L., Ang, S., \& Liu, W. T. (2004). Quantum dots as a novel immunofluorescent detection system for Cryptosporidium parvum and Giardia lamblia. Applied Environmental Microbiology, 70, 597-598. http://dx.doi.org/10.1128/AEM.70.1.597-598.2004 